\title{
COMPENSAÇÃO AMBIENTAL NA CRIAÇÃO E IMPLANTAÇÃO DE UNIDADES DE CONSERVAÇÃO NO ESTADO DE SÃO PAULO: $O$ CASO DOS PARQUES ESTADUAIS DO 'PANTANINHO PAULISTA', BRASIL.
}

\author{
Andréa Soares Pires ${ }^{1}$
}

Helder Henrique de Faria ${ }^{2}$

Resumo: Um dos assuntos mais angustiantes para os conservacionistas é quando se debate sobre financiamento dos projetos e das ações para se lograr os objetivos de conservação; sem dúvida este é um dos problemas mais crônicos no processo de criação e implantação de unidades de conservação da natureza no Brasil. Políticas públicas ambientais bem delineadas proveram um suspiro ao sistema gerencial nacional através das compensações ambientais, geradas em função da degradação ambiental provocada por empreendimentos públicos e privados. Este trabalho apresenta o caso da criação e implantação de dois parques estaduais - Aguapeí e Rio do Peixe no estado de São Paulo com recursos quase que exclusivamente advindo destes mecanismos financeiros. Apresenta-se o ambiente, o processo de criação, o planejamento e a implantação de ações e propostas técnico-científicas direcionadas a proteger e conservar uma amostra significativa de habitats e espécies de áreas úmidas.

${ }^{1}$ Bióloga MSc, Instituto Florestal/SMA.deapires@yahoo.com.br

${ }^{2}$ Eng. Florestal Dr., Instituto Florestal/SMA. MMADRE-Unoeste.helderdefaria@gmail.com 


\section{Introdução}

A conservação da biodiversidade representa um dos maiores desafios da humanidade, em função do elevado nível de perturbações antrópicas dos ecossistemas naturais. Originalmente a Mata Atlântica cobria cerca de 1,2 milhões $\mathrm{km}^{2}$, atualmente cobre cerca de $1.306 .421 \mathrm{~km}^{2}$ e desses somente 2,7\% protegida na forma de Unidades de Conservação. A Mata Atlântica de hoje se apresenta como um mosaico composto por poucas áreas relativamente extensas, principalmente na região sudeste e uma porção bem maior composta de áreas em diversos estágios de degradação (Lino et. al., 2012 p.)

Em termos regionais, o Estado de São Paulo possui dois biomas de grande relevância mundial, a Mata Atlântica e o Cerrado, conhecidos como Hotspots, estes biomas abrigam cercam de $78 \%$ das espécies da lista oficial brasileira de fauna silvestre ameaçada de extinção (Mittermeier et.al., 2004). Com os maiores índices de urbanização e industrialização do país, o Estado de São Paulo sofreu com uma intensa exploração dos recursos naturais no seu território, fragmentando estes biomas em meio a diversos usos da terra.

Nascida para a proteção da natureza em sentido amplo, a criação e manejo das unidades de conservação (UC) avançou como técnica e ciência e conta hoje com objetivos tão variados quanto à preservação da diversidade biológica, a manutenção de serviços ecológicos essenciais, a proteção de monumentos naturais e belezas cênicas associadas à promoção de pesquisa científica, educação, recreação, turismo ecológico e desenvolvimento regional, além de um importante instrumento de controle do território, já que estabelece limites e dinâmicas de uso e ocupação específicos (Milano, 1999; BRASIL, 2000; Medeiros, 2005).

O Brasil, como país de maior biodiversidade do mundo, utiliza-se atualmente das diferentes categorias de unidades de conservação e outras formas de proteção do ambiente para cumprir com os objetivos nacionais de conservação e uso sustentável dos recursos naturais renováveis. Para amparar tal política o país envida esforços na construção de mecanismos que viabilizem o respaldo financeiro do sistema ambiental nacional. Neste sentido, instituiu-se a necessidade de licenciamento ambiental dos empreendimentos que porventura causem danos ambientais irreversíveis, que devem ser devidamente aquilatados para reversão de recursos financeiros sob a forma preventiva presente nos fundamentos do principio Poluidor-Pagador (Faria, 2008). 
De acordo com o art. 36, da Lei oㅜ 9.985, de 18 de julho de 2000, que instituiu o Sistema Nacional de Unidades de Conservação - SNUC (BRASIL, 2000), ela consiste na obrigação de o empreendedor, nos casos de licenciamento ambiental de significativo impacto ambiental, apoiar a implantação e manutenção de unidades de conservação (UCs), auxiliando na consolidação da Política Nacional de Biodiversidade, cujo substrato estrutural materializa-se com essas ações (Milaré e Artigas, 2006).

De acordo com Dias (2011) a compensação ambiental, além de desempenhar o papel de instrumento econômico por meio do qual o Poder Público determina a inclusão da variante ambiental no planejamento econômico de um empreendimento, constitui também mecanismo de consolidação do Sistema Nacional de Unidades de Conservação. Ao permitir a criação de novas UCs e a estruturação daquelas já existentes, os recursos provenientes da compensação ambiental contribuem de forma significativa para a estruturação do órgão gestor das UCs, para a construção dos instrumentos de gestão (plano de manejo, conselho gestor, saneamento fundiário, operacionalização, investimentos, dentre outros) e, conseqüentemente, para o fortalecimento da gestão de todo o sistema de unidades de conservação.

Neste contexto estão inseridas as unidades de conservação apresentadas neste trabalho - o ambiente, o processo de criação, planejamento e a implantação de ações e propostas técnico-científicas direcionadas a proteger e conservar uma amostra significativa de habitats e espécies de áreas úmidas. Muitas das informações apresentadas neste trabalho são oriundas dos planos de manejo destas UCs, disponíveis em http://www.fflorestal.sp.gov.br/planodemanejoCompletos.php (IF, 2010a; IF 2010b), coordenados pelos autores do presente artigo e que envolveu ampla participação da sociedade.

\section{Criação dos Parques do "Pantaninho Paulista"}

Grandes rios de São Paulo deságuam no rio Paraná e em suas confluências formamse grandes banhados e várzeas, lugares sujeitos aos regimes hídricos dos rios, com a formação de ricos ecossistemas de elevada produção orgânica. Isto acontecia naturalmente, mas mesmo com a formação dos lagos pelas usinas hidroelétricas do rio Paraná o fenômeno persiste. 
Os alagadiços presentes na foz dos rios Aguapeí e Peixe passaram a ser denominados, regionalmente, de "Pantaninho Paulista", um epíteto popular em função das características geomorfológicas e a presença de muitas espécies da fauna característica do Pantanal Mato-grossense. Com elevada diversidade biológica, a região foi esquecida das políticas públicas direcionadas à conservação, salvo a criação da Reserva Estadual Lagoa São Paulo, instituída em 1942, mas que nunca foi efetivamente implantada pelo estado, sendo quase completamente submersa pelas águas do lago da usina hidroelétrica (UHE) Sergio Motta.

Em decorrência dos impactos ambientais gerados por esta UHE, em 1998 os Ministérios Públicos, Estadual e Federal, adiantando-se aos órgãos de licenciamento do estado, firmaram um Termo de Ajustamento de Conduta com a Companhia Energética de São Paulo - CESP, compelindo esta empresa a criar e implantar duas UCs de proteção integral na região impactada, garantindo repasses financeiros anuais e obras de infraestrutura. Deste modo foram criados dois Parques Estaduais de acordo com o SNUC (Brasil, 2000), ambos na categoria II da União Internacional para a Conservação (Dudley, 2008). Os Parques são zona core da Reserva da Biosfera da Mata Atlântica e se inserem em uma região de elevada prioridade para a criação de unidades de conservação e outras estratégias de intervenção que visem a conservação biológica (MMA, 2000; Projeto Biota/Fapesp www.biota.org.br/info/wap2006).

O Parque Estadual do Aguapeí (PEA) foi instituído pelo Decreto Estadual №43.269, de 02 de julho de 1998 (SÃO PAULO, 1998), com área de 9.043,970 hectares, entre as

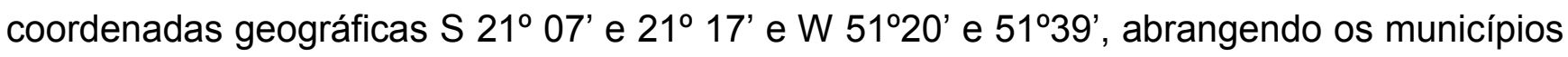
de Castilho, São João do Pau d'Alho, Nova Independência, Monte Castelo, Guaraçaí e Junqueirópolis, cujo conjunto apresenta uma população total de aproximadamente 50 mil habitantes.

O Parque Estadual do Rio do Peixe (PERP) foi criado pelo Decreto Estadual №47.095, de 18 de setembro de 2002 (SÃO PAULO, 2002), com área de 7.720,000

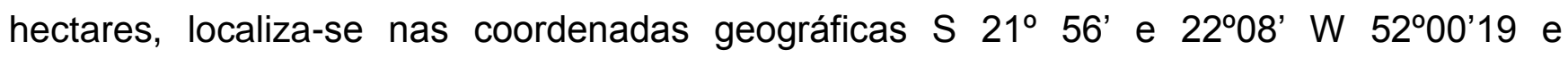
$52^{\circ} 00^{\prime} 03^{\prime \prime}$, nos municípios de Ouro Verde, Dracena, Presidente Venceslau e Piquerobi, com população total superior a 90 mil habitantes.

Ademais dos parques Aguapeí e Rio do Peixe criados em São Paulo em função da UHE Sergio Mota, a CESP foi comprometida a criar mais 20.000 ha de reservas devido aos impactos da UHE Três Irmãos, porém com incidência sobre região distante da impactada. De 
acordo com a Deliberação Consema n 007/2003, a CESP terá que ampliar a área do Parque Estadual do Rio do Peixe em 4.100 ha além de verba de $R \$ 50.000,00$ anuais, adicional aos $R \$ 200.000,00$ anuais, destinados à manutenção das áreas dos Parques Estaduais do Rio Aguapeí e do Rio do Peixe. Além disso, a CESP deverá prover infra-estrutura, cerca e guarita para o P.E. Rio do Peixe e para área remanescente da Lagoa São Paulo."

\section{Planejamento ambiental dos PPP}

Estrategicamente a implantação e planejamento do PERP e PEA foram divididos em três fases: curto, médio e longo prazo (quadro 1), de acordo com as prioridades executáveis e recursos humanos e financeiros disponíveis. O planejamento e a implementação em fases possibilita a estruturação progressiva da capacidade administrativa e cria a oportunidade para a Unidade estabelecer sua própria identidade.

Quadro 1 - Fases de planejamento e implantação de ações previstas na compensação ambiental referente à instalação e operação da UHE Sérgio Motta

\begin{tabular}{|c|c|}
\hline AÇÃO & FASE \\
\hline Abertura de conta e depósito anual & Curto prazo (2000)* \\
\hline Aquisição de equipamentos e máquinas & Curto prazo (2004) \\
\hline Construção de cercas & Curto prazo (2004 a 2005) \\
\hline Abertura de aceiros corta-fogo & Curto prazo (2004 a 2006) \\
\hline $\begin{array}{c}\text { Fiscalização da área, com manutenção sistemática de } \\
\text { guardas-parque do Estado }\end{array}$ & \begin{tabular}{c} 
Curto prazo (2005 a 2007) \\
\hline Detalhamento das necessidades de gestão
\end{tabular} \\
\hline Demarcação e delimitação da área & Médio prazo (2000 a 2007) \\
\hline Aquisição de novas glebas & Médio prazo (2000 a 2004) \\
\hline Elaboração do Plano de Manejo & Médio prazo (2007 a 2010) \\
\hline Implantação das ações propostas no Plano de Manejo & Médio prazo (2007 a 2010) \\
\hline no PEA & Longo prazo (2011 a 2015) \\
\hline nolantação das ações propostas no Plano de Manejo & Longo prazo (2011 a 2015) \\
\hline
\end{tabular}

* O valor de $\mathrm{R} \$ 50.000,00$ em 2004, ajustado redundou em 4.351,61 UFESP's, que somados aos valores referentes à UHE Eng. Sérgio Motta totalizam 28.246,47 UFESP's por ano, a serem destinados aos PPP durante o tempo que a UHE Sergio Motta gerar energia. Em 2012 esta quantia resultou cerca de $\mathrm{R} \$ 520.000,00$ por ano para o custeio e investimentos nos PPP, valor bastante razoável para parques recém criados 
Volume 8, Número 3, 2012

Biodiversidade e

Unidades de Conservação

O processo para a elaboração dos Planos de Manejo iniciou-se efetivamente em março de 2008, a consolidação dos planos ocorreu em 2009 e, finalmente, foram aprovados pelo CONSEMA em julho de 2010. O planejamento teve como referência roteiros confeccionados pela Fundação Florestal se adaptando as diretrizes do Roteiro Metodológico do IBAMA (2002); a elaboração de propostas e estratégias de ação fundamentou-se na participação social e na utilização da ferramenta denominada SWOT (ameaças e oportunidades, fraquezas e fortalezas - Harvard Business Scholl) para a análise das especificidades do manejo da área.

Um Plano de Manejo é um instrumento de planejamento que se caracteriza por ser flexível, dinâmico, contínuo, gradativo e participativo. Estas características permitem que, na medida em que se adquiram mais conhecimentos sobre a UC, mude-se o grau de intervenção no seu manejo. O fluxo de atividades (Figura 01) denota quatro grandes momentos do processo: a formação da equipe e os levantamentos básicos através da Avaliação Ecológica Rápida (Sobrevila y Bath, 1992); a participação comunitária através de oficina de planejamento SWOT; a consolidação técnica do plano e, por último, a defesa, revisão e publicação do documento.

\section{FLUXO DE ATIVIDADES}

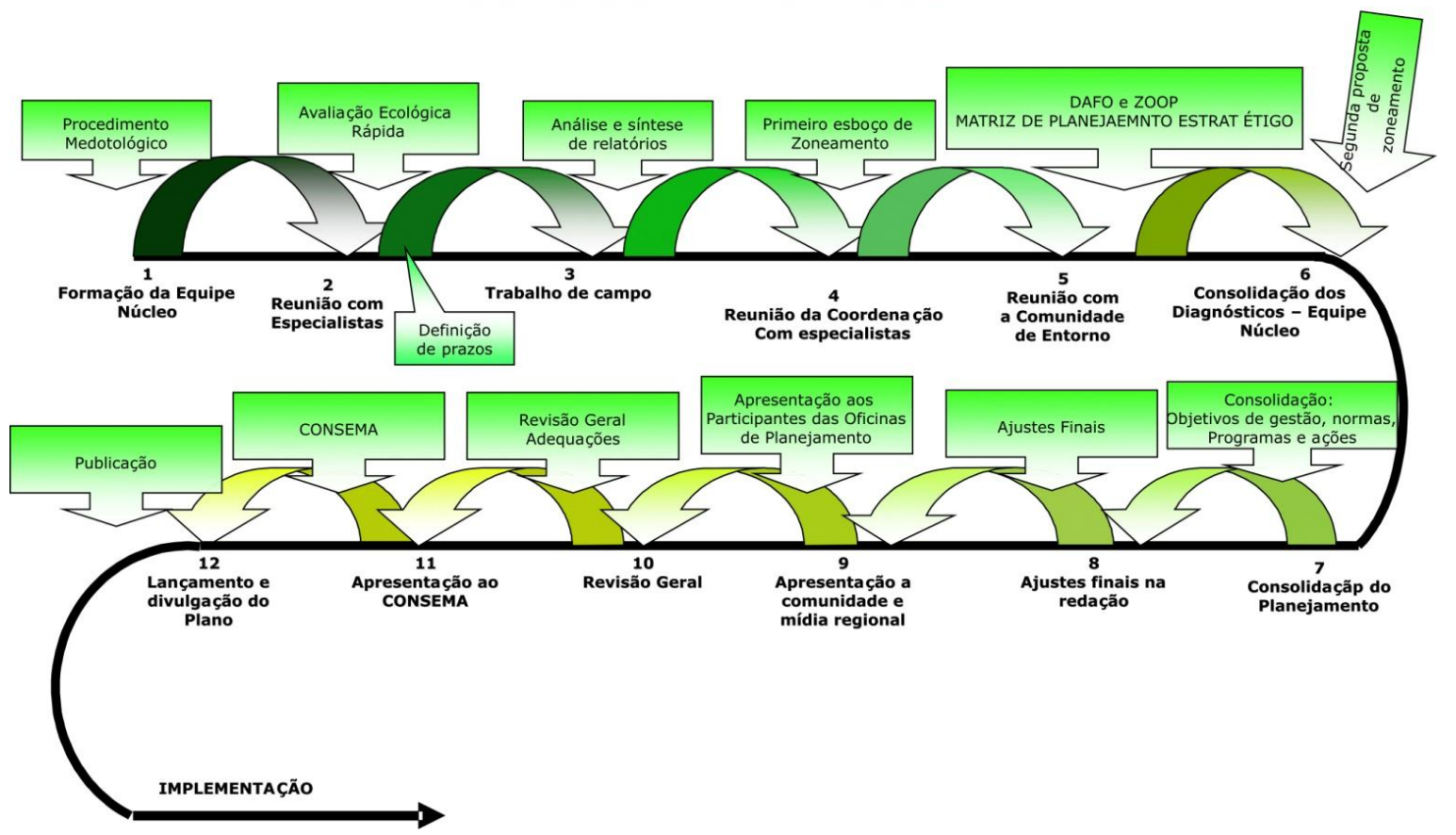

Figura 01 - Etapas da elaboração e implementação do Plano de Manejo dos Parques Aguapeí e Rio do Peixe. 
Foi construída uma base cartográfica digital, em dois níveis de abordagem espacial: a)local, abrangendo apenas a unidade de conservação, com produtos finais editados na escala 1:50.000 e

b)regional, abrangendo os $10 \mathrm{~km}$ definidos na Resolução CONAMA 13/90, com produtos finais editados na escala1:100.000.

Para a abordagem local, foram elaborados os seguintes mapas temáticos: hipsométrico, de classes de declividade, de atributos geológicos, de Unidades geomorfológicas e de fitofisionomias, acrescidos da hidrografia e malha viária.

Para que fosse possível, em curto prazo, levantar a flora associada a cada uma das fisionomias da vegetação dos Parques, adotou-se o método de caminhamento, primeiramente proposto por Filgueiras et al. (1994). Através de caminhadas dirigidas às bordas e ao interior de cada uma das fisionomias, foram registradas todas as espécies arbóreas observadas, coletando-se material botânico de todas as espécies cuja identificação em campo não fosse possível, para posterior comparação com material depositado em Herbários, ou para consulta a especialistas.

Para a escala regional, foram acrescidos aos temas anteriores a carta pedológica e a de uso das terras. Inicialmente, foram combinados dados cartográficos relativos à topografia, nas escalas 1:50.000 (Kronka et.al, 2005) e 1:5.000 (Base, 2006 - Ortofotos georreferenciadas, adquirida pelo processo SMA 41.762/2006).

O levantamento de dados primários contou com a participação dos guardas-parque do PEMD e equipe de pesquisadores contratados, através de expedições de campo e campanhas de fiscalização, além da aquisição, georreferenciamento e mapeamento de temas não existentes para UC. Já os dados secundários foram levantados da bibliografia e mapas existentes para área. Ao longo desta etapa foi realizado todo o diagnóstico ambiental sob o foco de diferentes temas, onde especialistas de diferentes áreas apresentaram suas sugestões acerca do ordenamento territorial e das atividades possíveis de execução em sua área.

Os resultados obtidos na etapa descrita anteriormente puderam ser apresentados à comunidade local e regional, através das Oficinas de Planejamento Estratégico, realizadas nos municípios de Dracena (20/11/2008) e Presidente Venceslau (21/11/2008), contando com a participação de 52 cidadãos e 43 organizações de atuação local/regional envolvidas com as questões ambientais. 
Volume 8, Número 3, 2012

Biodiversidade e

Unidades de Conservação

As Oficinas tiveram o objetivo de esclarecer o significado de um Parque Estadual e sua importância no contexto estadual/nacional, obter a percepção dos mesmos sobre a Unidade de Conservação e verificar como as organizações de atuação local/regional poderiam cooperar na sua gestão e conservação, dando início ao processo de ouvir a sociedade na definição de propostas. Nestas oficinas os trabalhos seguiram os princípios do Enfoque Participativo, envolvendo um conjunto de instrumentos desenvolvidos com a finalidade de facilitar o processo de comunicação e troca de experiências e conhecimentos.

As discussões resultaram grande diversidade de propostas que foram sistematizadas, analisadas quanto à viabilidade técnica e institucional de implantação e avaliadas em relação aos cenários interno e externo.

Finalmente, após a consolidação técnica dos objetivos de gestão, do zoneamento ambiental e dos programas de gestão e a obtenção da primeira versão impressa do Plano de Manejo, realizou-se a última Oficina de Planejamento, na sede do município de Dracena em 31 de julho de 2009. Para esta reunião foram instadas todas as organizações participantes das oficinas anteriores, mais algumas posteriormente identificadas pela equipe de planejamento, culminando na participação de 37 cidadãos e 25 organizações. Esta última Oficina resultou na aprovação consensual dos planos de manejo presente documento dos dois Parques Estaduais.

Vale ressaltar que a superfície da zona de amortecimento do PEA e do PERP foram definidas em 58.000ha e 56.000ha respectivamente, território em que se garante maior incidência dos mecanismos e ferramentas úteis á gestão ambiental do território.

A avaliação estratégica dos Parques apontou que as UCs estão em um estagio de sobrevivência (figura 02), com ameaças associadas aos pontos fracos, potencializadas na medida em que não existe recursos humanos para "cuidar" satisfatoriamente das mesmas. 
PONTOS FRACOS

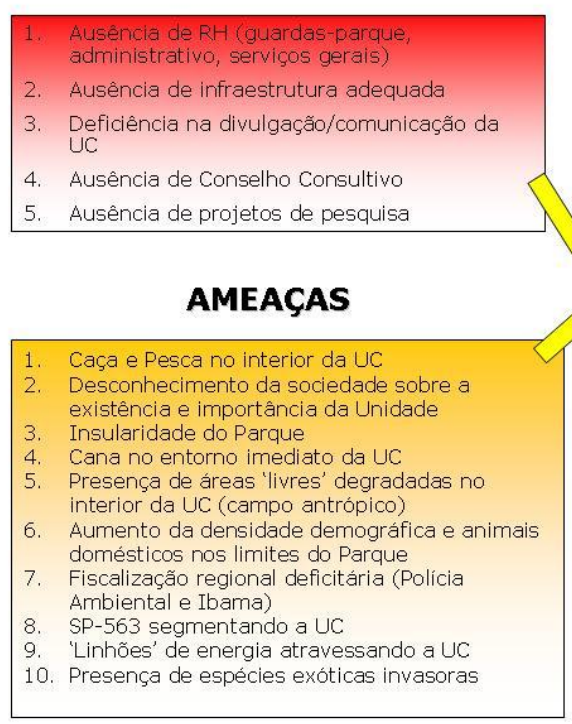

OPORTUNIDADES

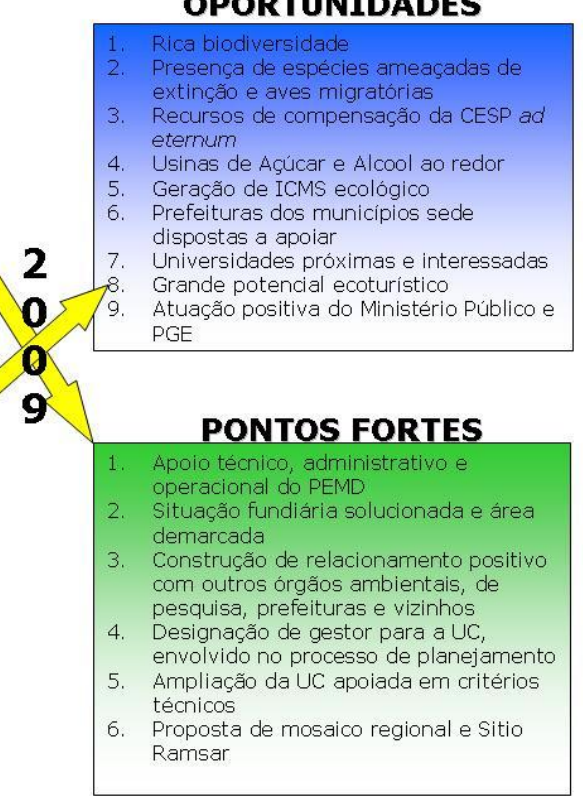

Diagnóstico = sobrevivência

Figura 02 - Análise SWOT realizada no processo de planejamento do território das unidades de conservação

Seguindo as diretrizes emanadas pelo Sistema Nacional de Unidades de Conservação da Natureza e considerando o conhecimento revelado pelos diagnósticos e análises produzidas pelos especialistas, os objetivos de gestão dos Parques foram definidos como sendo:

> Conservar amostra de Mata Atlântica de Interior - "Pantaninho Paulista" e proteger o Blastocerus dichotomus;

> Fomentar a conectividade ecológico-florestal e o resgate de hábitats degradados;

> Propiciar e apoiar a prática da educação ambiental e o desenvolvimento de pesquisas científicas;

Fomentar e apoiar o lazer e o ecoturismo.

A caracterização e analise da estrutura da paisagem (incluindo aspectos físicos, biológicos e ecológicos) foram a base para o zoneamento dos Parques. Nesta etapa definiram-se as áreas de maior fragilidade, áreas destinadas à recuperação de habitat, principalmente para o Cervo-do-Pantanal (Blastocherus dichotomus), e necessidades de 
Volume 8, Número 3, 2012

Biodiversidade e

Unidades de Conservação

infra-estrutura. Foram considerados parâmetros de conservação da biodiversidade, ecoturismo, proteção de bacias, monitoramento da qualidade ambiental e pesquisa científica. O delineamento da Zona de Amortecimento partiu dos 10 quilômetros preconizados pela Resolução Conama 13/90; excluiu as áreas urbanas; considerou as implicações determinadas pela hipsometria e vertentes, as possibilidades de conectividade e a proximidade de áreas úmidas e fragmentos florestais nas vizinhanças.

Sobre ambos os parques incidiram seis tipos de zonas, sendo que a zona conflitante refere-se às estradas de rodagem existentes no interior das UCs (Quadro 02).

Quadro 02 - Área correspondente a cada zona de manejo

\begin{tabular}{|l|l|l|l|l|}
\hline \multicolumn{1}{|c|}{ Zona de Manejo } & \multicolumn{1}{|c|}{$\begin{array}{c}\text { PEA } \\
\text { Área (ha) }\end{array}$} & $\begin{array}{c}\text { PEA } \\
\text { \% da área total }\end{array}$ & $\begin{array}{l}\text { PERP } \\
\text { Área (ha) }\end{array}$ & $\begin{array}{l}\text { PERP } \\
\% \quad \text { da área } \\
\text { total }\end{array}$ \\
\hline Intangível & 64,16 & 0,71 & 5,07 & 0,05 \\
\hline Primitiva & $6.516,18$ & 72,05 & $5.651,31$ & 58,07 \\
\hline Uso extensivo & 392,12 & 4,33 & 385,03 & 3,96 \\
\hline Recuperação & $2.035,35$ & 22,51 & $3.661,17$ & 37,62 \\
\hline Conflitante & 6,51 & 0,07 & 13,46 & 0,14 \\
\hline Uso especial & 29,65 & 0,33 & 15,14 & 0,16 \\
\hline $\begin{array}{l}\text { TOTAL } \\
\text { *considerando a área a ser ampliada na UC }\end{array}$ & $9.043,97$ & 100 & $9.731,24^{*}$ & 100 \\
\hline
\end{tabular}

Em função da similaridade ambiental dos PPP, da proximidade entre eles, da metodologia de planejamento adotada e da oportunidade de se implantar um sistema para a gestão integrada dos mesmos, muitas das ações programáticas são comuns a ambos, que assim agrupadas permite uma análise conjunta. $O$ quadro 03 mostra uma síntese destes programas e das principais ações a serem desenvolvidas ao longo do tempo. 
Quadro 03 - Ações previstas nos Planos de Manejo dos Parques Estaduais do Aguapeí e Rio do Peixe.

PRINCIPAIS AÇÕES POR PROGRAMA DE GESTÃO

PROGRAMA DE MANEJO DO MEIO AMBIENTE

SUBPROGRAMA MANEJO DE RECURSOS

Controle de espécies exóticas de flora e fauna

Monitoramento do entorno

Monitoramento de espécies ameaçadas de extinção

Conexão de fragmentos e revegetação de áreas internas

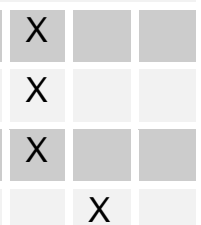

Recuperação de aeras degradadas no interior dos Parques

Restauração de habitat

\section{SUBPROGRAMA DE PROTEÇÃO}

Definição de pontos prioritários para fiscalização e executar

Verificar os limites das UCs

Sistematizar o controle de incêndios e articular com outras organizações prioridades de combate

PROGRAMA DE CONHECIMENTO

SUBPROGRAMA DE PESQUISA

Inventariar as espécies de mastofauna, avifauna, herpetofauna, entomofauna, com estimativa populacional

Desenvolver programas de monitoramento das espécies ameaçadas

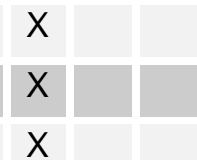

Realizar novos levantamentos florísticos nas áreas

A partir da abertura das áreas ao público, realizar o diagnóstico turístico das UCs e seus entornos

\section{SUBPROGRAMA DE MONITORAMENTO}

Realizar o monitoramento integrado da área, dos fenômenos bióticos e abióticos e das pesquisas $\quad X \quad X \quad X$ em andamento

PROGRAMA DE USO PÚBLICO

\section{SUBPROGRAMA DE EDUCAÇÃO AMBIENTAL}

Desenvolver a comunicação ambiental com a comunidade vizinha

Desenvolver atividades educativas em parceria com as organizações do Conselho Consultivo, $\mathrm{X}$ principalmente com os moradores da zona de amortecimento

Planejar e implantar infra-estrutura para recepção do público (trilhas, banheiros, playground, $\mathrm{X}$ alojamento, centro de visitantes)

SUBPROGRAMA DE ECOTURISMO

Elaborar Plano Estratégico de Ecoturismo 
PROGRAMA DE INTEGRAÇÃO COM ENTORNO

SUBPROGRAMA ALTERNATIVAS DE DESENVOLVIMENTO

Manter estreitas relações de trabalho com as organizações que atuam na região

Apoiar e fomentar iniciativas que visem melhorar a paisagem do entorno

SUBPROGRAMA COOPERAÇÃO INSTITUCIONAL

Montar e fazer funcionar o Conselho Consultivo

Envolver comunidade na criação e implantação de Sitio Ramsar

$\mathrm{X}$

$\mathrm{X}$

$\mathrm{X}$

$\mathrm{X}$

\section{PROGRAMA DE OPERAÇÕES}

SUBPROGRAMA DE ADMINISTRAÇÃO

Estabelecer e fiscalizar as rotinas administrativas

$X$

Envidar todos os esforços para que as demais ações e atividades elencadas em cada subprograma $X$ sejam cumpridas adequadamente

Implantar as ações previstas no Plano de Manejo

$\mathrm{X} \times \mathrm{X}$

SUBPROGRAMA DE DESENVOLVIMENTO DA UC

Implantar equipamentos de comunicação e infra-estrutura para atender as ações previstas nos $\mathrm{X}$ demais subprogramas

*Prazos: C - curto; M - médio; L - longo

\section{Características sócio-ambientais}

Uma pesquisa de opinião revelou que mais de $90 \%$ dos entrevistados nos municípios sede dos Parques reconhece a importância de se manter áreas destinadas à preservação ambiental no território. No entanto, mais de $65 \%$ da população desconhece a existência das áreas protegidas, aspecto que remete à necessidade de se investir em estratégias de comunicação e educação ambiental dirigida.

A vegetação natural das duas unidades é representada por um mosaico de fitofisionomias em áreas inundáveis e não inundáveis que margeia tanto o rio do Peixe quanto o rio Aguapeí e também por florestas ripículas associadas a pequenos cursos d'água (Quadro 04). A formação Floresta Estacional Semidecidual e seus diferentes estágios de conservação e regeneração representam 2.436,69 hectares no PERP e 3433,44ha no PEA. Já as formações vegetais características de várzeas somam 2.293,22 hectares no PERP e 3.105,07ha no PEA, favorecendo espécies da avifauna aquática típica de áreas úmidas, ademais do cervo do pantanal. 
Quadro 04 - Áreas ocupadas pelas fisionomias de vegetação PEA e PERP

\begin{tabular}{|l|l|l|l|l|}
\hline Fisionomia & $\begin{array}{l}\text { PEA } \\
\text { Área (ha) }\end{array}$ & $\begin{array}{l}\text { PERP } \\
\text { Área (ha) }\end{array}$ & $\%$ \\
\hline Campo Antrópico & $2.062,62$ & 22,81 & $2.045,93$ & 26,50 \\
\hline Cana-de-Açúcar & 10,95 & 0,12 & 283,24 & 3,67 \\
\hline Floresta Estacional Semidecidual (FES) & 976,44 & 10,80 & $1.265,17$ & 16,39 \\
\hline Vegetação Secundária da FES & $1.937,73$ & 21,82 & 908,50 & 11,77 \\
\hline FES em estágio inicial de regeneração & 519,27 & 5,74 & 263,02 & 3,40 \\
\hline Formação Arbórea/Arbustiva/Herbácea de Várzea & $3.105,07$ & 34,33 & $2.293,22$ & 29,70 \\
\hline Vegetação aquática & 64,80 & 0,72 & 4,77 & 0,06 \\
\hline
\end{tabular}

O entorno dos PPP é composta principalmente por uma matriz de pastagem plantada para criação de gado, que vem sendo substituída gradativamente pelo cultivo de cana-deaçúcar. Fragmentos isolados de floresta estacional semidecidual, com área entre cerca de 10 e 1000 ha, estão distribuídos nas duas matrizes anteriores e foram identificados para fins de conservação, estando hoje protegidos pelas Zonas de Amortecimento. Estes fragmentos apresentam intensas alterações abióticas, no entanto, assumem um importante papel ecológico, por atuar como refugio e corredores ecológicos para a flora e a fauna e garantir o fluxo genético de certos organismos entre fragmentos, além de manter espécies representativas da heterogeneidade biótica do bioma (Machado \& Fonseca, 2000; Strier 2000, Tabanez \& Viana 2000).

A região caracteriza-se por clima tropical quente e úmido, com precipitação média anual de $1.250 \mathrm{~mm}$. A temperatura média anual superior a 18 C으 (Instituto Florestal, 2010).

Os parques localizam-se na Província do Planalto Ocidental, com os rios de maior porte mostrando planícies aluviais de dimensões variadas (Soares et all, 1980; Suguio, 1980). No interior dos parques predominam as Planícies Aluviais, e o relevo de Colinas Amplas aparece em menor proporção, representando os terrenos mais altos adjacentes ao longo das planícies aluvionares.

A paisagem dos PPP lhes confere grande potencial ecoturístico, evidenciado nas expedições de campo durante a fase de planejamento, quando os especialistas puderam contemplar toda a paisagem marginal e uma enorme diversidade de fauna. $O$ percurso meândrico dos rios, com suas margens definidas por barrancos e vegetação florestal, reduz o campo de visão da pessoa embarcada e gera expectativas quanto aos cenários adiante. Isto, somado à facilidade de se avistar e observar a biodiversidade desde os rios dá sentido à 
denominação popular dos Parques e já motiva conversas sobre os negócios possíveis de existir de modo sustentável, principalmente prefeituras e clubes de serviço.

As características naturais conferem aos dois Parques Estaduais enorme diversidade faunística, facilmente avistada durante as atividades embarcadas. Os levantamentos no Plano de Manejo das áreas somam 38 espécies da mastofauna, sendo que aproximadamente metade das espécies observadas encontra-se sob algum grau de ameaça no Estado de São Paulo, o que indica a grande descaracterização ambiental na região.

Em relação à avifauna são 236 para o PERP e 238 no $P E A$, em relação à herpetofauna são 46 no PERP e 47 no PEA; já a ictiofauna apresenta 73 espécies no PEA. Desta biodiversidade total, mais de 40 são espécies que se encontram listadas em alguma categoria de ameaça no Estado de São Paulo (São Paulo, 2008).

Merecem destaque as populações de jacaré-do-papo-amarelo (Caimanlatirostris), dos ciconídeos como o maguari (Ciconia maguari), o tuiuiú (Jabiru mycteria) e o cabeça-seca (Mycteria americana); as anhumas (Anhimacornuta), o mutum de penacho (Craxfasciolata), o papagaio-galego (Amazona xanthops), arara-canindé (Ara ararauna), dentre outras que podem ser observadas com freqüência nos dois parques. Da mesma forma que grupos de capivaras (Hydrochaerishydrochaeris), biguás (Phalacrocoraxbrasilianus) e biguatingas (Anhinga anhinga), além de diversas espécies de anatídeos (IF 2010a; IF 2010b).

O cervo-do-pantanal (Blastocerusdichotomus) é a espécie símbolo dos Parques e representa um desafio previsto nos planos de manejo, pois a proteção dos ambientes e a inibição da caça deverão proporcionar um razoável aumento da sua população, que atualmente é diminuta.

\section{Ameaças Antrópicas}

Os Parques Aguapeí e Rio do Peixe, apesar de protegidos por lei, enfrentam sérios problemas ambientais, principalmente em função do uso dado às terras do entorno. A pecuária extensiva praticada na região há décadas se caracteriza pelo baixo investimento em formação e manutenção de pastagem, gerando destruição de ecossistemas ambientais, uma vez que o esgotamento ou a baixa produtividade de determinadas áreas incentiva a expandir seus domínios sobre biomas naturais; degradação do solo, erosões, assoreamento e contaminação de mananciais com nitrogênio, fósforo, potássio, hormônios, metais pesados e patógenos carregados para o leito dos rios pela lixiviação do solo. 
A cultura canavieira já domina o entorno dos Parques e os principais problemas ambientais estão relacionados à queima dos canaviais, aos tratos culturais e a fertirrigação.

A pesca ilegal e a caça é uma realidade freqüente nos Parques Aguapeí e Peixe. A captura de aves de estimação e canoras é uma prática corriqueira nas vizinhanças e dentro dos Parques, algumas ameaçadas de extinção, sendo a mais comum o papagaio-verdadeiro (Amazona aestiva). A caça de espécies para troféu e/ou consumo da carne afeta da mesma forma espécies importantes, como o cervo-do-pantanal (Blastocerusdichotomus), o jacarédo-papo-amarelo (Caimanlatirostris), a paca (Cuniculus paca) entre outros.

É de conhecimento coletivo que os rios Aguapeí e Peixe recebem cargas poluidoras provenientes de esgotos gerados pelas cidades e indústrias situadas ao longo das respectivas bacias hidrográficas, o que certamente interfere na qualidade das águas que adentram os limites dos Parques e, conseqüentemente, ocasionando danos à fauna e na cadeia alimentar dependente deste recurso.

As principais ameaças biológicas na região dos Parques Aguapeí e Rio do Peixe consistem na presença de espécies invasoras. Dentre as espécies exóticas introduzidas identificadas até o momento há uma representante vegetal, o bambu (Bambusa vulgaris) e duas espécies animais, o peixe bagre-africano (Clarias gariepinus) e o molusco caramujoafricano (Achatina fulica).

O bambu foi introduzido há muito tempo, provavelmente por agricultores no intuito de conter processos erosivos e se alastrou por toda a extensão de ambos os parques, com maior incidência no Peixe. Atualmente se mescla à vegetação nativa, sobre a qual parece avançar.

A introdução do bagre africano no Brasil foi para criação em cativeiro e chegou aos grandes rios da maioria do Estado de São Paulo. Atualmente representa fator extremamente negativo à ictiofauna nativa, por ser uma espécie altamente resistente e voraz, prolifera-se rapidamente e compete com as espécies nativas, ameaçando de extinção local espécies menores de peixes.

O caramujo-africano foi descoberto recentemente nos parques, provavelmente por pescadores que a utilizam como isca. Restrito a alguns focos, prolifera-se com incrível velocidade, podendo representar um risco à fauna silvestre, uma vez que transporta agentes patogênicos e compete por alimentação com a fauna herbívora. Numa das extremidades do PEA foram avistados exemplares de porcos domésticos que fugiram de seus criadouros, tornando-se semi-selvagens e competindo por recursos com as espécies nativas. Estes 
componentes deverão ser alvo de pesquisas e projetos na busca de soluções aos problemas.

\section{Implantação}

A implantação dos planos de manejo precisa ser desejada como ação política organizacional, sendo necessários múltiplos esforços para se desenvolver as propostas de gestão, pois nos dias atuais é quase que utópico imaginar que os governos e agências 'carimbem' recursos específicos para a sua efetiva implementação.

Os planos de manejo dos PPP são pragmáticos e exeqüíveis, no entanto, apesar de existirem recursos financeiros disponíveis para as áreas, advindos de diferentes compensações ambientais e principalmente a da CESP, não está ocorrendo a agilidade organizacional necessária para o bom uso desses recursos. As formas de tramitar essas demandas têm sofrido reveses que emperram as execuções e realizações, confundindo-se o necessário seguimento das normas da administração pública com os excessos burocráticos ainda presentes nas organizações de estado.

O quadro 05 mostra o volume de recursos ministrados em ambos os parques por medidas compensatórias.

\begin{tabular}{|c|c|c|c|c|c|}
\hline $\begin{array}{l}\text { Empreendedor } \\
\text { Instrumento } \\
\text { formal }\end{array}$ & UC & $\begin{array}{c}\text { Proc. } \\
\text { Licenciamento }\end{array}$ & Valor & Objetivo & Situação \\
\hline $\begin{array}{l}\text { CESP } \\
\text { TAC }\end{array}$ & PEA/PERP & $\begin{array}{ll}\text { Termo } & \text { de } \\
\text { Ajustamento } & \text { de } \\
\text { Conduta } & \end{array}$ & $\begin{array}{l}28.246,47 \\
\text { UFESP's por } \\
\text { ano }\end{array}$ & $\begin{array}{l}\text { Adquirir e Criar } \\
\text { PEA e PERP; } \\
\text { adquirir } \\
\text { equipamentos; } \\
\text { construir sedes; } \\
\text { prover recursos } \\
\text { de custeio } \\
\text { anuais }\end{array}$ & $\begin{array}{l}\text { Recursos } \\
\text { depositados. } \\
\text { Fundação } \\
\text { Florestal com } \\
\text { problemas } \\
\text { burocráticos para } \\
\text { operacionalização }\end{array}$ \\
\hline $\begin{array}{l}\text { Usina Clealco } \\
\text { TCCA }\end{array}$ & PEA/PERP & SMA 13.679/2003 & $\mathrm{R} \$ 300.000,00$ & $\begin{array}{l}\text { Planos de } \\
\text { Manejo }\end{array}$ & Finalizado \\
\hline $\begin{array}{l}\text { Usina Dracena } \\
\text { TCCA }\end{array}$ & PERP & SMA 13.607/2003 & $\mathrm{R} \$ 245.000,00$ & Administração & Finalizado \\
\hline Usina Viralcool & PEA/PERP & SMA n 13.812/06 & $\mathrm{R} \$ 742.560,00$ & Fiscalização & Finalizado \\
\hline Usina Da Mata & PEA/PERP & $\begin{array}{ll}\text { SMA } & n^{\circ} \\
13.628 / 2007 & \end{array}$ & $\mathrm{R} \$ 641.666,40$ & $\begin{array}{l}\text { Comunicação e } \\
\text { Educação } \\
\text { Ambiental }\end{array}$ & Iniciado \\
\hline
\end{tabular}


A participação comunitária e de organizações sociais no planejamento gerou sentimento de cidadania e estimulou a criação dos Conselhos Consultivos, empossados ainda no ano de 2009, ao fim do processo de planejamento. Com cerca de 30 organizações representadas nos dois conselhos, as reuniões ocorrem periodicamente e tem resultado em medidas efetivas e enérgicas, tal como a inibição de propostas governamentais de instalar unidades prisionais na zona de amortecimento do PE Aguapeí, por exemplo (CC-PEA, 2011).

Tanto o PEA como o PERP contam com apenas um gestor e não existem recursos humanos lotados nas UCs, o que atualmente é o maior entrave para a gestão de melhor qualidade. Repercute duvidosamente o fato de a CESP prever a entrega das sedes de ambos os Parques em 2013, sendo que a Fundação Florestal todavia não sinalizou como ocupará os prédios novos. Desde sua criação os PPP estão muito próximos do que se denomina "parques de papel", pois as ações são muito pontuais e, dado a falta de RH e de estratégias solidas para a implantação dos planos de manejo, os olhares dos gestores se fixam sobre o que seja possível fazer e o mais prioritário, agindo então sobre os licenciamentos ambientais do entorno e realizando palestras em escolas e clubes de serviço da região.

Ou seja, a estes técnicos são atribuídas as funções administrativas relativas aos documentos públicos, cuidar da fiscalização das áreas, da comunicação com a sociedade, organizar e controlar as pesquisas, atentar para a implementação, controle e prestação de contas dos recursos de compensação ambiental, etc. etc. atividades cuja somatória não permite que todas as ações se produzam com êxito e eficácia. Não adianta existir dinheiro se não há gente e condições para se tocar a toada.

\section{Considerações Finais}

A iniciativa das Promotorias Públicas, Estadual e Federal, revela um exemplo a ser seguido pelos demais representantes distribuídos pelo Brasil, na medida em que propuseram a ação cível e reconheceram a necessidade de estarem alicerçados tecnicamente por profissionais da Secretaria de Meio Ambiente, que os muniram dos conhecimentos afeitos à criação, implantação e gestão de áreas protegidas, sem o que não teriam como aquilatar os requerimentos para os novos Parques Estaduais. Note-se que o compromisso se estende ad eternum, enquanto a usina hidroelétrica gerar energia, algo que parece inédito no país. 
A Fundação Florestal tem o grande desafio de implantar e tornar eficazes os Parques Estaduais do Aguapeí e Rio do Peixe. Eles são belos e de extrema importância para a conservação da biodiversidade paulista, uma lacuna preenchida antes mesmo que os cientistas 'descobrissem' suas maravilhas naturais. Juntamente com as outras unidades de conservação do "pantaninho paulista" configuram um mosaico, cuja agenda comum se pauta no ordenamento ambiental do território, a conservação de habitats e espécies da fauna e o desenvolvimento sustentável.

É substancial dizer que stakeholders de elevada influência e eminência regional reconhecem os benefícios que essas áreas geram, mostrando-se simpáticos e comprometidos, como de fato já se materializa, em auxiliar na conservação e desenvolvimento dos parques Aguapeí e Rio do Peixe, o que facilitará a solução de problemas/ameaças e maximização das ações benfazejas.

\section{Referencias}

BRASIL. Lei Federal n $n^{\circ}$ 9.985, de 18 de julho de 2.000. Diário Oficial da União, 2000. P 1-6, 19 de jul. de 2000.Seção I. Regulamenta o artigo 225, $1^{\circ}$ - incisos I, II, III e IV da Constituição Federal, institui o Sistema Nacional de Unidades de Conservação da Natureza e dá outras providências.

DIAS, Roberta Leocácio. 2011. Compensação Ambiental em Unidades de Conservação de Uso Sustentável. Revista Jus Navegandi. Disponível em: http://jus.com.br/revista/texto/20126/. Acessado em 10 de outubro de 2011.

Dudley, N. and S. Stolton. 2003. "Ecological and socio-economic benefits of protected areas in dealing with climate change". In: Hansen, L.J., J.L. Biringer and J.R. Hoffman (Eds) Buying Time: A user's guide to building resistance and resilience to climate change in natural systems, pp. 217-233. Washington, DC: WWF US.

FARIA, Ivan Dutra. COMPENSAÇÃO AMBIENTAL: Os fundamentos e as normas; a gestão e os conflitos. 2008. http://www.senado.gov.br/senado/conleg/textos discussao/TD43-IvanDutraFaria.pdf, acessado em 4/09/2012

INSTITUTO BRASILEIRO DO MEIO AMBIENTE E DOS RECURSOS NATURAIS RENOVÁVEIS. 2002. "Roteiro metodológico de planejamento, Parque Nacional, Reserva Biológica, Estação Ecológica". Brasília, 135p.

INSTITUTO FLORESTAL. 2010a. Plano de Manejo do Parque Estadual do rio do Peixe. Coord. Helder de Faria e Andréa Pires. Vários autores. Deliberação CONSEMA 17, de 21/07/2010 - Aprova o Relatório da Comissão Especial de Biodiversidade, Florestas, Parques e Áreas Protegidas, favorável ao Plano de Manejo do Parque Estadual do Rio do Peixe elaborado pelo Instituto Florestal,. 
Secretaria de Estado do Meio Ambiente. São Paulo, SP. D.O.E. de 31/07/2010. Seção I, 120 (144), pág. 46.

INSTITUTO FLORESTAL. 2010b. Plano de Manejo do Parque Estadual do Aguapeí. Coord. Helder de Faria e Andréa Pires. Vários autores. Deliberação CONSEMA 18, de 21/07/2010 - Aprova o Relatório da Comissão Especial de Biodiversidade, Florestas, Parques e Áreas Protegidas, favorável ao Plano de Manejo do Parque Estadual do Rio do Peixe elaborado pelo Instituto Florestal,. Secretaria de Estado do Meio Ambiente. São Paulo, SP. D.O.E. de 31/07/2010. Seção I, pág. 47.

KRONKA,José Francisco do Nascimento; NALON, Marcos; MATSUKUMA,CiroKoity; KANASHIRO, Marina Mie; YWANE, Maria; PAVÃO,Mônica; DURIGAN,Giselda; LIMA, Leni Meire Pereira; GUILLAMON,João Régis; BAITELLO,João Batista; BORGO,Sérgio Camargo; MANETTI, Lucila; BARRADAS,Angéilica M.F; FUKUDA,Juliana Cristina; SHIDA,Cláudia Nagako; MONTEIRO,Cláudio Henrique Barbosa; PONTINHA,Ananias A.; ANDRADE,Gina G.; BARBOSA, Onildo; PIRES, Andréa Soares; JOLY, Carlos Alfredo; COUTO, Hilton ThadeuZaratte do. 2005. Inventário florestal da vegetação natural do Estado de São Paulo. Instituto Florestal, São Paulo. Imprensa Oficial do Estado de São Paulo. 200p.

LINO, Clayton Ferreira; ALBUQUERQUE, João Lucílio R. de.; DIAS, Heloisa; SCHAFFER, Wigold Bertolo; PROCHNOW, Miriam; LIMA, Patricia Ferreira e. Anuário da Mata Atlântica 2012 - Panorama do Cumprimento das Metas de Aichi - CDB 2020 na Mata Atlântica: Avanços, Oportunidades e Desafios. RBMA. 2012.

MACHADO, R. B., AND G. A. B. DA FONSECA. 2000. The avifauna of Rio Doce Valley, southeastern Brazil, a highly fragmented area. Biotropica 32: 914-924.

Mapa geomorfológico do Estado de São Paulo, escala 1:500.000. São Paulo - SP, Instituto de Pesquisas Tecnológicas do Estado de São Paulo, Vol. 1e Vol. 2.

MILARÉ, Edis e ARTIGAS, Priscila Santos. Compensação Ambiental: questões controvertidas. Revista de Direito Ambiental. Ano 11, no 43, julho-setembro de 2006. Coordenação: Antônio Herman V. Benjamin e Edis Milaré. Editora RT.

MINISTÉRIO DO MEIO AMBIENTE. 2000. Avaliação e ações prioritárias para a conservação da biodiversidade da Mata Atlântica e Campos Sulinos. 40 pp. acessado em 28/03/2009. http://www.mma.gov.br

MITTERMEIER, Russel A.; GIL, Patrício Robles; HOFFMAN, Michael; PILGRIN, John; BROOKS, Thomas; MITTERMEIER, Cristina Goesttsh; LAMOREUX, John; FONSECA, Gustavo A.B. da. 2004. Hotspots Revisited: Earth's Biologically Richest and Most Endangered Terrestrial Ecoregions. Universityof Virgínia. CEMEX, S.A.

SÃO PAULO. 21 Programas Ambientais Estratégicos. Acessado em 28/03/2009. http://www.ambiente.sp.gov.br/projetos.php 
Decreto no 54.079 de 04 de março de 2009. altera artigos e modifica os Anexos do Decreto $n^{\circ} .51 .453$ de 29 de dezembro de 2006. Diário Oficial do Estado de São Paulo. acessado em 03/10/2008. www.imprensaofical.com.br

. Decreto $n^{\circ}$. 43.269, de 02 de julho de 1998.Cria o Parque Estadual do Aguapeí, declara de utilidade pública as áreas necessárias e dá providências correlatas. Diário Oficial do estado de São Paulo - acessado em 28/03/2009:www.imprensaofical.com.br

. Decreto $\mathrm{n}^{\circ} .51 .453$ de 29 de dezembro de 2006. Cria o Sistema Estadual de Florestas SIEFLOR e dá outras providências. Diário Oficial do Estado, Poder executivo, Seção I. 116(247):3738. 2006

. Decreto no. 53.494, de 2 de outubro de 2008. Declara as Espécies da Fauna Silvestre Ameaçadas, as Quase Ameaçadas, as Colapsadas, Sobrexplotadas, Ameaçadas de Sobrexplotação e com dados insuficientes para avaliação no Estado de São Paulo e dá providências correlatas. Diário Oficial do estado de São Paulo - acessado em 03/10/2008. www.imprensaofical.com.br

.Decreto №. 47.095, de 18 de setembro de 2002 Cria o Parque Estadual do Rio do Peixe. Diário Oficial do Estado de São Paulo - acessado em 28/03/2009:www.imprensaofical.com.br

SECRETARIA DO MEIO AMBIENTE DO ESTADO DE SÃO PAULO. 186a Reunião Ordinária de 16/04/2003 do Conselho Estadual de Meio Ambiente. Acessado em 28/03/2009. www.ambiente.sp.gov.br

SOARES, P.C. et al. 1980. Ensaio de caracterização estratigráfica do Cretáceo no Estado de São Paulo: Grupo Bauru. Revista Brasileira de Geociências(1980), 10(3): 177-185.

STRIER, K. B. 2000. Population viabilities and conservation implications for Muriquis (Brachyteles aracnoides) in Brazil's Atlantic Forest. Biotropica 32: 903-913.

SUGUIO K., FÚLFARO V.J., AMARAL G., GUIDORZI L.A. 1977. Comportamentos estratigráficos e estrutural da Formação Bauru nas regiões administrativas 7 (Bauru), 8 (São José do Rio Preto) e 9 (Araçatuba) no Estado de São Paulo. In: SBG/Núcleo SP, Simpósio de Geologia Regional, I, São Paulo, Atas, $231-247$.

TABANEZ, A. A. J., AND V. M. VIANA. 2000. Patch structure within Brazilian Atlantic Forest fragments and implications for conservation. Biotropica 32: 925-933. 